\title{
Evaluation and treatment of dyspepsia
}

\author{
M P Jones
}

Postgrad Med J 2003;79:25-29

Dyspepsia is a common symptom. Dyspeptic symptoms may be caused by a variety of conditions such as peptic ulcer disease, gastro-oesophageal reflux, and malignancy. Most often, however, no cause is identified and dyspepsia is deemed to be functional. While symptom severity does influence frequency of consultation, dyspeptic consulters also differ from non-consulters with respect to symptom perception and anxiety. This highlights the importance of understanding the patient's agenda early in the course of evaluation. Patients over the age of 55 years or with alarm symptoms should be referred for prompt endoscopy. In the absence of other clinically apparent aetiologies, uninvestigated dyspeptics can be either tested and treated for Helicobacter pylori or empirically treated with proton pump inhibitors. Uninvestigated dyspeptics failing empiric therapy should be referred for evaluation that includes endoscopy. Further therapy with prokinetics, tricyclic antidepressants, fundal relaxants, antidepressants, or psychotherapy is guided by predominant symptoms and assessment of possible psychiatric factors.

Correspondence to: Dr Michael P Jones, 251 East Huron St, Galter Pavilion 4-104, Chicago, IL $60611-2908$, USA mpjones@nmh.org

Submitted 23 August 2002 Accepted

31 October 2002

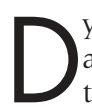
spepsia literally means "bad digestion" and it's a problem that most of the population has experienced at some point in their lives. While most of us have experienced dyspepsia, the symptoms we've had likely differed in timing, nature, severity, and impact on our lives. Additionally, for most, dyspepsia is simply a symptom while for others it's a manifestation of underlying disease. This is the dilemma of dyspepsia: a common problem with multiple manifestations caused by a variety of things or by nothing at all.

\section{DEFINING THE PROBLEM}

Defining dyspepsia is like describing a close relative-easily recognised but difficult to describe. A variety of criteria exist. Most define dyspepsia as symptoms arising from the upper digestive tract unrelated to colonic function. Often symptoms are brought on or worsened by eating. The Rome II consensus report, a recent widely cited effort symptomatically categorising functional digestive disorders, defines dyspepsia as pain or discomfort centred in the upper abdomen. ${ }^{1}$ Discomfort specifically includes early satiety, fullness, upper abdominal bloating, and nausea. "Functional" dyspepsia (synonymous with "non-ulcer" dyspepsia) is defined by these same authors as 12 weeks in the past 12 months of persistent or recurrent pain or discomfort in the upper abdomen in the absence of organic disease and no association with bowel habit.

Functional dyspepsia may be further categorised by predominant symptoms into ulcer-like, dysmotility-like, and unspecified dyspepsia. Ulcer-like dyspepsia has pain as the predominant symptom while dysmotility-like dyspepsia has predominantly abdominal discomfort. A previous category of reflux-like dyspepsia is no longer included since most of these patients actually have reflux disease and should be managed as such. It is worth noting that this classification scheme was primarily developed as an aid in the design and performance of clinical trials. Its clinical utility beyond taxonomy remains unproven.

Defining dyspepsia allows for more accurate study of the problem and the problem is considerable. Studies from the United States, Great Britain, and other parts of the world have shown the prevalence of dyspepsia to be between $26 \%$ and $41 \% .^{23}$ While only $20 \%-25 \%$ of these individuals seek medical care, dyspepsia accounts for $2 \%-5 \%$ of all consultations in primary care. ${ }^{4}$ For gastroenterologists, dyspepsia accounts for between $20 \%$ and $40 \%$ of consultations. ${ }^{5}$ It appears that as primary care physicians have grown more comfortable with proton pump inhibitors and Helicobacter pylori eradication, the percentage of attendees in gastroenterology clinics with functional dyspepsia is steadily increasing.

The burden of illness with respect to quality of life and economic consequences of dyspepsia is considerable. Recent data from a large cross sectional survey in the UK suggest dyspepsia may be costing society approximately $£ 1$ billion ( $\$ 1.46$ billion) annually. ${ }^{6}$ Similar estimates exist for the costs of diagnosis and management of dyspepsia in the United States. ${ }^{7}$ A Swedish study estimated direct costs of dyspepsia to be approximately $£ 26$ million annually for 8 million people. ${ }^{8}$ When indirect costs were included, total costs increased almost 10 -fold. This was largely attributable to the average of 26 (!) more days of lost productivity by dyspeptics. Indirect health costs are parallelled by decreased quality of life, which can be profound. ${ }^{6910}$ Figure 1 shows Psychological General Well Being index scores for healthy controls, patients with functional dyspepsia, and gastroparetics seen in our clinic. Clearly, the burden of dyspepsia is considerable from economic, societal, and personal vantage points.

\section{EARLY INVESTIGATION AND} MANAGEMENT OF THE "UNINVESTIGATED DYSPEPTIC"

Dyspepsia is a symptom and not a diagnosis. The differential diagnosis of dyspepsia is shown in 


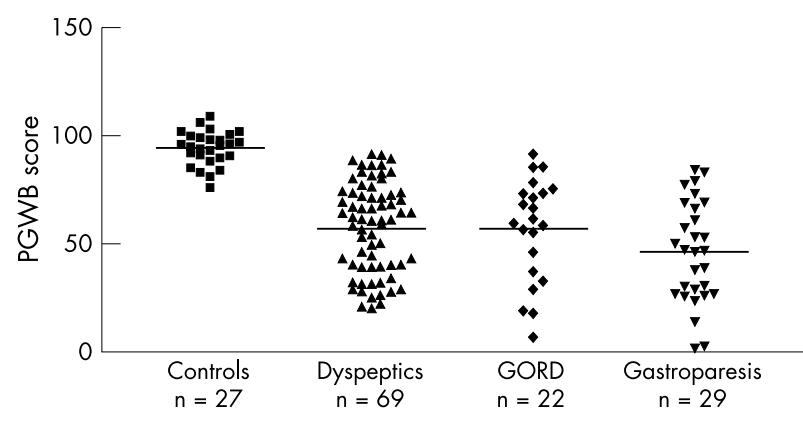

Figure 1 Quality of life in functional dyspepsia, proton pump inhibitor-refractory gastro-oesophageal reflux disease (GORD), and gastroparesis. Psychological General Well Being (PGWB) scores are significantly lower in patients with dyspepsia, GORD, and gastroparesis compared with controls ( $p<0.001$ for all).

\section{Box 1 : Differential diagnosis of dyspepsia}

- Non-ulcer dyspepsia.

- Gastro-oesophageal reflux disease.

- Peptic ulcer disease.

- Medication related: non-steroidal anti-inflammatory drugs, antibiotics, iron, potassium supplements, digoxin.

- Carbohydrate malabsorption (lactose, fructose, sorbitol).

- Cholelithiasis or choledocholithiasis

- Chronic pancreatitis.

- Systemic disorders (diabetes, thyroid, parathyroid, hypoadrenalism, connective tissue disease).

- Intestinal parasites.

- Abdominal malignancy (especially pancreatic and gastric cancer).

- Chronic mesenteric ischaemia.

box 1 . While important clues to symptom aetiology may be obtained from interview and examination, symptom patterns alone do not discriminate organic from functional dyspepsia. ${ }^{11}$ In $50 \%-60 \%$ of cases, no cause is identified and patients are considered to have functional dyspepsia. ${ }^{12}{ }^{13}$ The prevalence of peptic ulcer disease is $15 \%-25 \%$ and oesophagitis prevalence is $5 \%-15 \% .{ }^{14}$ Upper digestive cancer is seen in typically $<2 \%$. Because cancer of the upper digestive tract is uncommon in Western countries under the age of 50, it is recommended those patients over the age of 55 be referred promptly for endoscopy. It is also recommended that patients with significant weight loss, gross or occult bleeding, dysphagia, severe vomiting, or profound early satiety also be referred for early endoscopy. ${ }^{13}$

Dyspepsia is a common sequelae of non-steroidal antiinflammatory medication use and these drugs are clearly ulcerogenic. Although most patients with dyspepsia taking non-steroidal anti-inflammatory drugs will not have ulcer, this cannot be predicted clinically. The most prudent course in these patients is to discontinue non-steroidals. If that cannot be done for valid clinical reasons, endoscopy should be performed.

Patients with dyspeptic symptoms who are not candidates for early endoscopy are termed "uninvestigated dyspeptics". These patients may be empirically treated most often using antisecretory or prokinetic agents. Antisecretory agents are preferred as they are better tolerated and effectively treat underlying gastro-oesophageal reflux disease or peptic ulcer disease. While $\mathrm{H}_{2}$ receptor antagonists have been widely used in this setting for many years, proton pump inhibitors should presently be regarded as first line agents. Proton pump inhibitors offer some superiority over $\mathrm{H}_{2}$ receptor antagonists in the treatment of peptic ulcer disease and are substantially superior in providing symptom relief in reflux disease. Given the inherent diagnostic uncertainty present when empirically

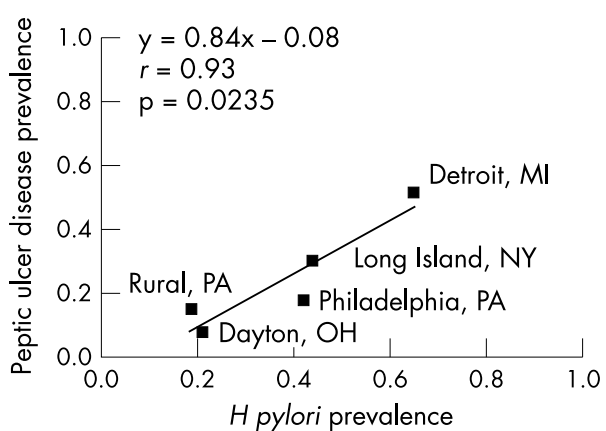

Figure 2 Variable prevalence of $H$ pylori and peptic ulcer disease in selected studies in the United States.

treating dyspepsia, it seems reasonable to not further complicate matters by adding the confounding variable of a suboptimal therapy. Additionally, there are now several studies with omeprazole and lansoprazole demonstrating superiority of these agents over $\mathrm{H}_{2}$ receptor antagonists in this setting. ${ }^{15-17}$ The optimal dose of proton pump inhibitor for a therapeutic trial is not known but given the desired goal of controlling gastric acid secretion and normalising the intraoesophageal $\mathrm{pH}$ profile, a twice daily dose of a newer proton pump inhibitor should probably be used. ${ }^{18}$

Some authors have advocated a symptom-tailored approach with proton pump inhibitors given to those patients with principal complaints of upper abdominal pain and prokinetics used initially in patients with fullness, bloating, or early satiety. ${ }^{19}$ There are no good clinical data to support this approach at present.

Because some dyspeptics will have underlying peptic ulcer disease that can be cured by eradication of $H$ pylori, the strategy of testing uninvestigated dyspeptics for $H$ pylori and treating those who are infected has become quite popular. Proponents have argued this strategy eliminates ulcer disease and is cost saving. ${ }^{132} 21$ The utility of this approach is obviously highly dependent upon the prevalence of $H$ pylori, the prevalence of peptic ulcer disease, the degree to which eradication of $H$ pylori improves symptoms of functional dyspepsia, and the cost and availability of alternative management strategies.

As shown in fig 2, the prevalence of $H$ pylori and peptic ulcer disease are highly correlated and vary considerably across the United States. H pylori and ulcer disease are quite common in urban Detroit but uncommon in suburban and rural practices in Ohio and Pennsylvania. ${ }^{22-26}$ Obviously, the utility of a test and treat strategy is dependent upon the prevalence of $H$ pylori in the specific population being treated. Additionally, despite some data to the contrary, the majority of well done clinical trials have failed to demonstrate symptom improvement in functional dyspepsia after $H$ pylori eradication. ${ }^{27}{ }^{28}$

In summary, patients with new onset dyspepsia who are over the age of 55 years or with alarm symptoms should undergo early endoscopy. In the remaining patients, the likelihood of organic pathology is low. "Uninvestigated dyspeptics" can be managed empirically. If the background prevalence of $H$ pylori and ulcer disease is high, a "test and treat" approach is reasonable. H pylori negative patients or those not responding to eradication therapy can be given a trial of proton pump inhibitors. If there is a clinical response to either acid suppressive therapy or $H$ pylori eradication, patients can be managed intermittently for recurrent symptoms. For patients who require additional reassurance, fail empiric therapy, or require chronic treatment, referral for further investigation including upper gastrointestinal endoscopy is indicated. 

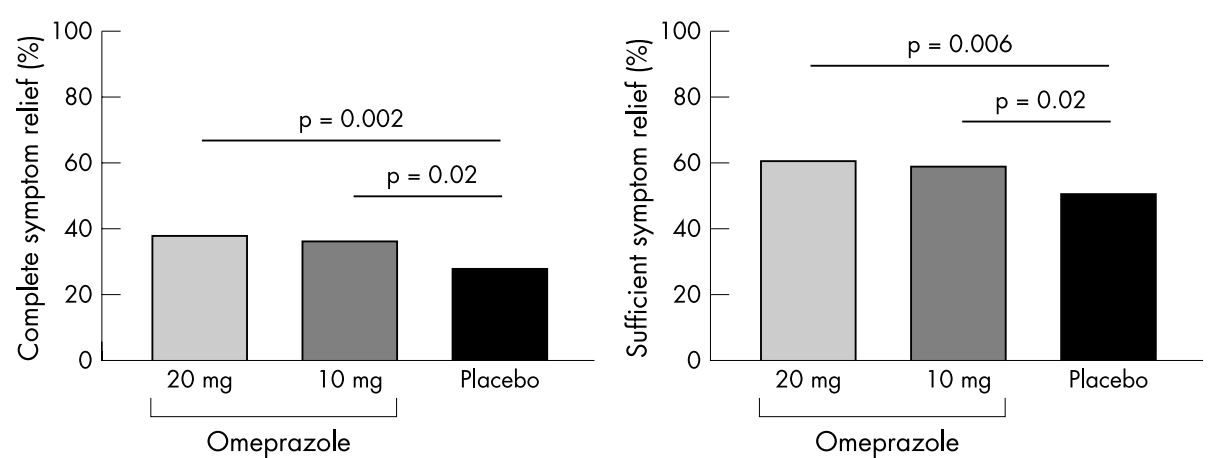

\section{Box 2: Potential causes of non-ulcer dyspepsia}

- Duodenogastric reflux.

- Duodenitis.

- Carbohydrate malabsorption (lactose, fructose, sorbitol).

- Cholelithiasis or choledocholithiasis.

- Chronic pancreatitis.

- Systemic disorders (diabetes, thyroid, parathyroid, hypoadrenalism, connective tissue disease).

- Intestinal parasites.

- Psychiatric disorders.

- Visceral hypersensitivity.

- Gastric/small intestinal dysmotility.

- Gallbladder/biliary dysmotility.

\section{INVESTIGATION OF DYSPEPSIA AND NON-ULCER DYSPEPSIA}

Eradication of $H$ pylori and use of acid suppressive therapy will benefit those patients with dyspepsia attributable to peptic ulcer and reflux disease. There additionally appears to be some benefit of acid suppression in true functional dyspepsia. Studies of functional dyspepsia that have aggressively excluded ulcer and reflux disease have tended to show little benefit from $\mathrm{H}_{2}$ receptor antagonists. More recent studies using proton pump inhibitors have demonstrated modest gains in more carefully selected patients. Omeprazole in both $10 \mathrm{mg}$ and $20 \mathrm{mg}$ doses was superior to placebo when using the endpoints of complete symptom relief or sufficient symptom control in two combined trials involving 1262 patients (fig 3). The net therapeutic gain was $10 \%$ for omeprazole $20 \mathrm{mg}$ daily and $8 \%$ for omeprazole $10 \mathrm{mg}$ daily. There was no significant difference between groups with respect to quality of life and the therapeutic benefits were restricted to those patients with ulcer-like or reflux-like dyspepsia. ${ }^{29} \mathrm{~A}$ third double blind, placebo control trial of omeprazole $20 \mathrm{mg}$ daily in 197 patients with functional dyspepsia showed omperazole to be superior to placebo in providing complete symptom relief after two weeks. ${ }^{30}$

For patients unresponsive to acid suppressive therapy or $H$ pylori eradication, mechanisms of symptom generation are largely speculative. This means therapeutic interventions are also speculative. A variety of potential causes have been proposed with varying degrees of support (box 2). While patients often complain of excess acid, there is no evidence for abnormal gastric acid secretion. The role of $H$ pylori has already been discussed. It should be kept in mind that "gastritis" is neither an endoscopic diagnosis nor a cause of recognised cause of dyspepsia.

Three aetiologies deserve particular attention: dysmotility, visceral hypersensitivity, and psychiatric disorders. Abnormalities of gastric neuromuscular function can be detected by scintigraphic gastric emptying studies, electrogastrography, or antroduodenal manometry in between $30 \%$ and $60 \%$ of patients. ${ }^{31-33}$ In addition to impaired motor function, a subset of dyspeptics has impaired postprandial relaxation of the proximal stomach. Some investigators have suggested that certain symptoms are associated with altered gastric physiology. Predictors of delayed gastric emptying include female sex, excessive postprandial fullness, and severe vomiting. ${ }^{32}$ Impaired postprandial relaxation of the proximal stomach has been associated with early satiety. ${ }^{34}{ }^{35}$ The acute administration of the interstitial serotonin receptor $\left(5-\mathrm{HT}_{1}\right)$ agonists, buspirone and sumatriptan, has been shown to improve accommodation and tolerance to balloon distension of the proximal stomach. ${ }^{35}{ }^{36}$ While these observations are encouraging, most studies have failed to demonstrate a relationship between disturbed gastrointestinal motor function and symptoms. In particular, there is little evidence that abnormalities of commonly employed tests of gastric function identify therapies that reliably improve symptoms.

Much recent attention has focused on the concept that patients with functional dyspepsia have augmented perception of visceral pain or visceral hypersensitivity. Many dyspeptics will report pain at levels of balloon distension in the stomach or proximal intestine that are not perceived as adverse by controls. ${ }^{37-39}$ These observations should be interpreted cautiously. Many of these studies have used protocols prone to response bias. Borrowing from studies of visceral hypersensitivity in irritable bowel syndrome, studies using less bias-prone methods tend to not demonstrate visceral hypersensitivity. This raises the possibility that much of visceral hypersensitivity is actually hypervigilence. ${ }^{40}$ Although tricyclic antidepressants have been shown to have efficacy in treating the hyperalgesia of irritable bowel syndrome and non-cardiac chest pain, there is presently no evidence for their efficacy in the treatment of non-ulcer dyspepsia. As visceral hypersensitivity is common to these disorders, use of tricyclics in functional dyspepsia would seem reasonable even if unstudied. Presently no controlled trials exist regarding the use of selective serotonin reuptake inhibitors in functional dyspepsia apart from their use to treat concomitant psychopathology.

The coexistence of psychiatric disturbances and dyspeptic symptoms is well documented. Importantly, it appears that dyspeptic consulters do not differ from non-consulters with respect to objective symptoms, but they tend to perceive their symptoms as more severe and have greater associated anxiety. ${ }^{41}$ The implication is clear-in managing functional dyspepsia, answers are less likely to be found by taking an ever more microscopic view of the digestive tract and more likely to be found by taking a more macroscopic view of the entire patient. Patients with psychiatric distress have a high prevalence of digestive symptoms. Conversely, patients with longstanding unexplained digestive symptoms are vulnerable to the development of reactive psychiatric disorders. Anxiety, depression, personality disorders, and a history of physical or sexual abuse are all seen with increased frequency in this population. ${ }^{42-44}$ Understanding these issues is critical to managing patients with functional disorders. The importance of addressing patient concerns and exploring the psychosocial context of symptoms cannot be overstated, particularly in 
patients refractory to standard therapies. Frank discussions in an empathic manner or use of self administered questionnaires such as the Beck Depression Index, Beck Anxiety Index, and Symptom Check List-90 can provide objective documentation that may help further explore these areas.

\section{TREATMENT OF NON-ULCER DYSPEPSIA}

Therapy in functional dyspepsia is symptom driven. There are few data to suggest that studies of gastric neuromuscular function allow implementation of therapies that reliably improve symptoms. Patients with functional dyspepsia who have predominant symptoms of upper abdominal pain (ulcerlike) can be initially treated with proton pump inhibitors. Patients with unexplained upper abdominal pain who have failed proton pump inhibitors may be treated with tricyclic antidepressants, although good supporting data are lacking.

Those with dysmotility-like symptoms can be treated initially with either acid suppressive therapy, prokinetic agents, or $5-\mathrm{HT}_{1}$ agonists. Both metoclopramide and domperidone have been shown to be superior to placebo in the treatment of functional dyspepsia. ${ }^{45}{ }^{46}$ Available literature suggests 5-HT agonists may be efficacious in patients with impaired accommodation. Since formal assessment of accommodation is not widely available, it is reasonable to use these agents in patients with excessive early satiety. The lack of supporting data and the adverse reactions associated with sumatriptan argue against the use of this agent. Buspirone has comparable effects, fewer adverse events, and may provide additional anxiolytic benefits in a non-confrontational way.

For all patients, the psychosocial context of symptoms should be assessed. Patients with a history of psychiatric distress, multiple unexplained physical symptoms, or symptoms refractory to standard therapies should be evaluated for concomitant psychopathology. If identified, appropriate therapy is offered. At present there are no data to support the use of selective serotonin reuptake inhibitors in functional dyspepsia in the absence of disorders for which these medications are otherwise indicated.

\section{SUMMARY}

Dyspepsia is a common symptom and is most often functional. Importantly, dyspeptic consulters differ from nonconsulters more in terms of symptom perception and anxiety than objective symptom measures. This highlights the importance of understanding the patient's agenda early in the course of evaluation. Patients over the age of 55 years or with alarm symptoms should be referred for prompt endoscopy. In the absence of other clinically apparent aetiologies, uninvestigated dyspeptics can be either tested and treated for $H$ pylori or empirically treated with proton pump inhibitors.

Uninvestigated dyspeptics failing empiric therapy should be referred for evaluation that includes endoscopy. Further therapy with prokinetics, tricyclic antidepressants, fundal relaxants, antidepressants, or psychotherapy is guided by predominant symptoms and assessment of possible psychiatric factors.

\section{Author's affiliation}

Gastroenterology and Physiology Laboratory, Division of

Gastroenterology, Feinberg School of Medicine, Northwestern University, Chicago, Illinois

\section{REFERENCES}

Talley NJ, Stanghellini $V$, Heading RC, et al. Functional gastroduodenal disorders. Gut 1999;45(suppl 2):॥37-42.

2 Jones R. Dyspeptic symptoms in the community. Gut 1989;30:893-8.

3 Talley NJ, Zinsmeister AR, Schleck CD, et al. Dyspepsia and dyspepsia subgroups: a population-based study. Gastroenterology 1992;102(4 pt 1):1259-68.

4 Brown C, Rees WD. Dyspepsia in general practice. BM 1990;300:829-30.
5 Tebaldi M, Heading RC. Clinical economics review: functional (non-ulcer) dyspepsia. Aliment Pharmacol Ther 1998:12:11-9. 6 Moayyedi P, Mason J. Clinical and economic consequences of dyspepsia in the community. Gut 2002;50(suppl 4):iv10-2.

7 Fennerty MB. Use of antisecretory agents as a trial of therapy. Gut 2002;50(suppl 4):iv63-6.

8 Nyren O, Adami HO, Gustavsson S, et al. Social and economic effects of non-ulcer dyspepsia. Scand J Gastroenterol Suppl 1985;109:41-7.

9 Talley NJ, Weaver AL, Zinsmeister AR. Impact of functional dyspepsia on quality of life. Dig Dis Sci 1995;40:584-9.

10 Drossman DA, Li Z, Andruzzi E, et al. US householder survey of functional gastrointestinal disorders. Prevalence, sociodemography, and health impact. Dig Dis Sci 1993;38: 1569-80.

11 Bytzer P, Hansen JM, Schaffalitzky de Muckadell OB, et al. Predicting endoscopic diagnosis in the dyspeptic patient. The value of predictive score models. Scand I Gastroenterol 1997:32:1 18-25.

12 Fisher RS, Parkman HP. Management of nonulcer dyspepsia. N Engl J Med 1998;339:1376-81.

13 American Gastroenterological Association. Medical position statement: evaluation of dyspepsia. Gastroenterology 1998;1 14:57981

14 Talley NJ, Silverstein MD, Agreus L, et al. AGA technical review: evaluation of dyspepsia. American Gastroenterological Association. Gastroenterology 1998;1 14:582-95.

15 Mason I, Millar L, Sheikh RR, et al. The management of acid-related dyspepsia in general practice: a comparison of an omeprazole versus an antacid-alginate/ranitidine management strategy. Compete Research Group. Aliment Pharmacol Ther 1998;12:263-71.

16 Jones RH, Baxter $\mathrm{G}$. Lansoprazole $30 \mathrm{mg}$ daily versus ranitidine 150 $\mathrm{mg}$ bd in the treatment of acid-related dyspepsia in general practice. Aliment Pharmacol Ther 1997;11:541-6.

17 Meineche-Schmidt V, Krag E. Antisecretory therapy in 1017 patients with ulcerlike or refluxlike dyspepsia in general practice. Eur J Gen Pract 1997; 3: 125-30.

18 Bell NJ, Burget D, Howden CW, et al. Appropriate acid suppression for the management of gastro-oesophageal reflux disease. Digestion 1992:51(suppl 1):59-67.

19 Talley NJ. Dyspepsia: management guidelines for the millennium. Gut 2002; 50(suppl 4):iv72-8.

20 Lam SK, Talley NJ. Report of the 1997 Asia Pacific Consensus Conference on the management of Helicobacter pylori infection. J Gastroenterol Hepatol 1998;13:1-12.

21 Talley NJ, Axon A, Bytzer P, et al. Management of uninvestigated and functional dyspepsia: a working party report for the World Congresses of Gastroenterology 1998. Aliment Pharmacol Ther 1999;13:1135-48.

22 Cutler AF, Havstad S, Ma CK, et al. Accuracy of invasive and noninvasive tests to diagnose Helicobacter pylori infection. Gastroenterology 1995;109:136-41.

23 Greenberg RE, Bank S. The prevalence of Helicobacter pylori in nonulcer dyspepsia. Importance of stratification according to age. Arch Intern Med 1990;150:2053-5.

24 Bruno J, Jones M. No Hp-no PUD. The importance of determining community prevalence rates of Helicobacter pylori in formulating clinical pathways for the evaluation of dyspepsia. Am J Gastroenterol 1997:92:A1610.

25 Faigel DO, Childs M, Furth EE, et al. New noninvasive tests for Helicobacter pylori gastritis. Comparison with tissue-based gold standard. Dig Dis Sci 1996;41:740-8

26 Kenney G, Paladino M, Davis B. The prevalence of Helicobacter pylori is low in rural northwestern Pennsylvania. Am J Gastroenterol 1997;92:A1617.

27 Talley NJ, Vakil N, Ballard ED, et al. Absence of benefit of eradicating Helicobacter pylori in patients with nonulcer dyspepsia. N Engl J Med 1999:341:1106-11.

28 Blum AL, Talley NJ, O'Morain C, et al. Lack of effect of treating Helicobacter pylori infection in patients with nonulcer dyspepsia. Omeprazole plus Clarithromycin and Amoxicillin Effect One Year after Treatment (OCAY) Study Group. N Engl J Med 1998;339:1875-81.

29 Talley NJ, Meineche-Schmidt V, Pare P, et al. Efficacy of omeprazole in functional dyspepsia: double-blind, randomized, placebo-controlled trials (the Bond and Opera studies). Aliment Pharmacol Ther 1998; 12:1055-65

30 Lauritsen K, Aaylkke C, Havelund T, et al. Effect of omeprazole in functional dyspepsia: a double-blind, randomized, placebo-controlled study. Gastroenterology 1996:110(suppl):A702.

31 Soykan I, Lin Z, Jones S, et al. Gastric myoelectrical activity, gastric emptying and correlations with dyspepsia symptoms in patients with gastroesophageal reflux. J Invest Med 1997;45:483-7.

32 Stanghellini V, Tosetti C, Paternico A, et al. Risk indicators of delayed gastric emptying of solids in patients with functional dyspepsia. Gastroenterology 1996;1 10:1036-42.

33 Malagelada JR, Stanghellini V. Manometric evaluation of functional upper gut symptoms. Gastroenterology 1985;88(5 pt 1):1223-31.

34 Tack J, Piessevaux H, Coulie B, et al. Role of impaired gastric accommodation to a meal in functional dyspepsia. Gastroenterology 1998; 115:1346-52.

35 Tack J, Coulie B, Wilmer A, et al. Influence of sumatriptan on gastric fundus tone and on the perception of gastric distension in man. Gut 2000;46:468-73

36 Coulie B, Tack J, Janssens J. Influence of buspirone-induced fundus relaxation on the perception of gastric distention in man Gastroenterology 1997;112:A715. 
37 Tack J, Caenepeel P, Fischler B, et al. Symptoms associated with hypersensitivity to gastric distention in functional dyspepsia. Gastroenterology 2001;121:526-35.

38 Holtmann G, Gschossmann J, Neufang-Huber J, et al. Differences in gastric mechanosensory function after repeated ramp distensions in non-consulters with dyspepsia and healthy controls. Gut 2000:47:332-6.

39 Salet GA, Samsom M, Roelofs JM, et al. Responses to gastric distension in functional dyspepsia. Gut 1998;42:823-9.

40 Whitehead WE, Palsson OS. Is rectal pain sensitivity a biological marker for irritable bowel syndrome: psychological influences on pain perception. Gastroenterology 1998:115:1263-71.

41 Lydeard S, Jones R. Factors affecting the decision to consult with dyspepsia: comparison of consulters and non-consulters. J R Coll Gen Pract 1989;39:495-8.
42 Langeluddecke P, Goulston K, Tennant C. Psychological factors in dyspepsia of unknown cause: a comparison with peptic ulcer disease. J Psychosom Res 1990;34:215-22.

43 Talley NJ, Fung LH, Gilligan IJ, et al. Association of anxiety, neuroticism, and depression with dyspepsia of unknown cause. A case-control study. Gastroenterology 1986;90:886-92

44 Talley NJ, Fett SL, Zinsmeister AR, et al. Gastrointestinal tract symptoms and self-reported abuse: a population-based study. Gastroenterology 1994;107:1040-9.

45 Dobrilla G, Comberlato M. Steele A, et al. Drug treatment of functional dyspepsia. A meta-analysis of randomized controlled clinical trials. J Clin Gastroenterol 1989:11:169-77.

46 Veldhuyzen van Zanten SJ, Cleary C, Talley NJ, et al. Drug treatment of functional dyspepsia: a systematic analysis of trial methodology with recommendations for design of future trials. Am J Gastroenterol 1996;91:660-73.

IMAGES IN MEDICINE.

\section{Perichondritis: a complication of piercing auricular cartilage}

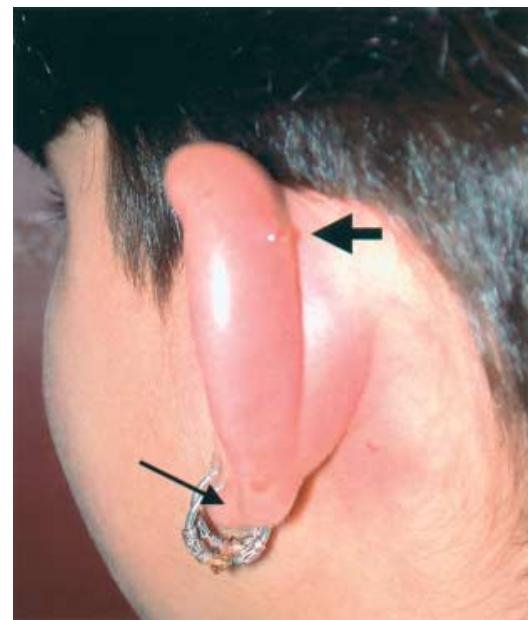

Figure 1 Perichondritis complicating "high" ear piercing. Two thirds of the upper part of the auricle is swollen and red (wide arrow). The lobule, which does not contain cartilage, is intact (long arrow) indicating that the infection is perichondritis and not simply cellulitis.

\begin{abstract}
A 20 year old woman presented to the ear, nose, and throat clinic with auricular perichondritis two days after piercing the helix of her left ear with the aid of a piercing gun. Two thirds of the upper part of her auricle was swollen, red, and tender. The lobule (which does not contain cartilage) remained intact, which indicated that the infection was perichondritis and not simply cellulitis (fig 1 ). The patient was treated with ciprofloxacin by mouth for a period of one week; by then the infection was entirely resolved.

Body piercing has become a widespread phenomenon in the last decade. Although other parts of the body have become subject to this new ritual of body piercing, the ear remains a most common site, with piercing of the ear cartilage ("high" ear piercing) gaining more popularity. Although the various parts of the auricle do not carry different risks for complications, the cartilage of the ear tends to become infected more often than the lobule after piercing. Staphylococcus aureus and Pseudomonas aeruginosa are the most common bacteria. ${ }^{1}$

The use of guns for piercing cartilage presents an additional risk of perichondritis. The gun applies shear forces to the perichondrium, which may slip off the cartilage. An avascular cartilage (which is normally nourished by the perichondrium), may then become necrotic. Abscess formation and loss of cartilage are potential complications that often require surgical intervention. Despite timely treatment, including antibiotic therapy, drainage, and debridement, an unsightly deformity ("cauliflower ear") may result.

The treatment of choice for auricular perichondritis is fluoroquinoline antibiotics, such as ciprofloxacin, since they show good antipseudomonal activity in addition to their effect against staphylococci. They also penetrate well into the cartilage. However, their use is limited to patients who are more than 18 years old because of their potential damage to young developing cartilage.

Although our treatment was successful, this case demonstrates the potential hazards of piercing cartilage, mainly in the ear and nose. Perichondritis can end with a very unsightly ear or nose, which may eventually turn out to be beyond repair. Physicians as well as the clientele of body piercers should be aware of this risk.
\end{abstract}

S Yahalom, R Eliashar Department of Otolaryngology/Head and Neck Surgery, Hadassah University Hospital, Jerusalem, Israe

Correspondence to: Dr Eliashar; ron@eliashar.com

\section{References}

1 Simplot TC, Hoffman HT. Comparison between cartilage and soft tissue ear piercing complications. Am J Otolaryngol 1998;19:305-10.

2 Smith RA, Wang J, Sidal T. Complications and implications of body piercing in the head and neck. Curr Opin Otolaryngol Head Neck Surg 2002;10:199-205. 